\title{
Effect of Surfactants on the Corrosion and Wear Performance of Zinc-Epoxy Powder Composite Coatings
}

\author{
Xian Yang ${ }^{1}$, Zhiming Gao $^{1, *}$, Xinyue Wang ${ }^{2}$, Wenbin $\mathrm{Hu}^{1}$ \\ ${ }^{1}$ Tianjin Key Laboratory of Composite and Functional Materials, School of Materials Science and \\ Engineering, Tianjin University, Tianjin, 300072 China \\ ${ }^{2}$ School of Materials Science and Engineering, Hebei University of Engineering, Hebei, 056006 China \\ *E-mail: gaozhiming@tju.edu.cn
}

doi: $10.20964 / 2021.07 .01$

Received: 9 March 2021 / Accepted: 26 April 2021 / Published: 31 May 2021

\begin{abstract}
To improve the corrosion and wear resistance of the coating, zinc-epoxy powder (EP) composite coatings were prepared by alkaline zincate electrodeposition. The surfactants of sodium dodecyl sulfate (SDS), cetyl trimethyl ammonium bromide (CTAB), dodecyl dimethyl benzyl ammonium chloride (1227) and polyvinylpyrrolidone (PVP) were used to disperse the EP, respectively. SEM and EDX analysis show that EP is successfully incorporated into the zinc coating. The incorporation of EP reduces the roughness of the $\mathrm{Zn}$ coatings. The corrosion resistance of the composite coating prepared by using surfactant is enhanced, which may be due to the adequate wetting contact between EP and zinc and the reduction of defects. The composite coating obtained by using SDS has the lowest root mean square roughness. The grain sizes of all coatings are similar. Electrochemical impedance spectroscopy shows that the composite coating with the strongest corrosion resistance obtained by using SDS, which has the largest coating resistance and charge transfer resistance. The addition of EP reduces the friction coefficient of the $\mathrm{Zn}$ coatings. The composite coating obtained by using CTAB has the lowest friction coefficient and wear scar width is reduced.
\end{abstract}

Keywords: zinc; epoxy powder; corrosion resistance; wear resistance.

\section{$\underline{\text { FULL TEXT }}$}

(C) 2021 The Authors. Published by ESG (www.electrochemsci.org). This article is an open access article distributed under the terms and conditions of the Creative Commons Attribution license (http://creativecommons.org/licenses/by/4.0/). 